\title{
Carotenoid Pigment: Significance as a Natural Food Colourant and Factors Affecting its Isolation
}

\author{
Anshu Sharma ${ }^{1 *}$, Anju Kumari Dhiman' ${ }^{2}$,Sachin Mittal $^{2}$, \\ Surekha Attri ${ }^{2}$ and Neeru Dubey ${ }^{3}$ \\ ${ }^{1}$ Amity International Centre for Post Harvest Technology and Cold Chain Management, Amity \\ University, Noida, UP, 201303, India \\ ${ }^{2}$ Department of Food Science and Technology, College of Horticulture, Dr YS Parmar \\ University of Horticulture and Forestry, Nauni, Solan, HP, 173230, India \\ ${ }^{3}$ AICPHT, Amity University, Noida, India \\ *Corresponding author
}

\section{A B S T R A C T}

\section{Ke ywords \\ Carotenoids, \\ Extraction \\ efficiency, Factors, \\ Health promoting, \\ Stability, Yield \\ Article Info \\ Accepted: \\ 04 January 2018 \\ Available Online: \\ 10 February 2019}

Carotenoids are the valuable bio-active constituent of many fruits and vegetables and are the most abundant group of pigments which are responsible for the yellow-orange pigmentation. Carotenoids play a potential role in human body by protecting cells and tissues from the damaging effects of free radicals and singlet oxygen. Researchers have reported that carotenoids may provide a variety of potential health-promoting functions. Therefore, these pigments have been used in the prevention or protection against human health disorders. Various natural sources have been explored in recent years with high concentration of carotenoid pigment. Factors such as moisture, particle size, temperature, enzyme, solid-solvent ratio, etc. affect the isolation efficiency, yield and stability of extracted pigment. This review highlights the effect of these factors on the isolation of carotenoids.

\section{Introduction}

The colour of raw and processed food products is extremely important. If the food does not taste good, people will not try it again but if it does not look good, they may not even try it at all. Food colours are often added to change the appearance of food by reducing colour loss that often happens from exposure to air, light, extreme temperature conditions or otherwise storage conditions. People use colour as a way to identify and judge the quality of food. From various studies it has been observed that colour of food or beverage can play a profound role in flavour perception (Lawrence et al., 2009). Many studies have emphasized the relation of colour with the flavour detection threshold, sweetness or salinity sensations and susceptibility and preference for products (Frick and Meggos, 1988; Clydesdale, 1993). So it is important to note that the colour of a food or beverage often dominates over other sources of information regarding the flavour.

In the last 20 years, synthetic colourants have been increasingly perceived undesirable by consumers (Downham and Collins, 2000). 
The current consumer preference for naturally derived colourants in food is because of their health promoting properties. Moreover, synthetic colours tend to impart undesirable taste and are harmful to human health. These colours lower haemoglobin concentration and red blood cell count, stimulate allergic reactions and inhibits dopamine uptake by nerve ending (reduced dopamine turnover). That is why synthetic colours have become a matter of prime concern (Bachalla, 2016). As a result, interest in the development of food colourants from natural sources as an alternative to synthetic dyes has increased (Ilker, 1987; Giusti, 1996; Dweck, 2009) and thus has become the focus of attention of many scientists all over the world.

Carotenoids are some of the most vital coloured pigments accounting for the attractive yellow orange colour of a variety of fruits and vegetables. Colouration of fruits and vegetables depends on their maturity, concentration of carotenoid isomers and food processing methods. The occurrence of carotenoids in plants is not as a single compound. Most of the carotenoids are bound with chlorophyll and a combination of carotene-chlorophyll and xanthophyllchlorophyll. The binding of carotenoids to chlorophylls can give rise to a variety of attractive colours in plants, fruits and vegetables (Rao and Rao, 2007). The major carotenoid responsible for yellow-orange colour in fruits and vegetables are beta $(\beta)$ carotene, lutein, lycopene, alpha $(\alpha)$ and cis$\beta$-carotene.

Some carotenoids have provitamin A activities. Vitamin A plays an important role in the vision, immune and reproduction system. Garewal et al., (1982) claimed that $\beta$ carotene acts as a suppressor of the Human Immunodeficiency Virus (HIV) and is a protective immunity agent against infectious disease such as measles (West et al., 1989).
Carotenoids are also present intracellularly and may be involved in the regulation of gene expression or affect cell functions like inhibition of monocyte adhesion and platelet activation (Devraj et al., 1996; Rock, 1997). These biological effects are independent of the provitamin A activity and have been attributed to the antioxidant property of carotenoids (Krinsky, 1989; Palozza and Krinsky, 1992). Highly pure carotenoid is commonly used in pharmaceutical products such as multi-vitamin tablets for gradual nutrient supplement or for patients with vitamin A deficiency. It is also combined with other ingredients in the formula of anti-cancer drugs.

Recently, food processors, technologists and bio-chemists have shown a great interest in the extraction, identification and purification of pigments from natural sources. Different extraction methods have been employed for extraction of carotenoids such as solvent extraction, soxhlet extraction and nonconventional methods of extraction. The implementation of pre-treatments over plant matrices has resulted in an increase in the quantity of extraction and lowered operating costs. The various factors such as moisture, particle size, solid-solvent ratio, temperature and enzymatic treatments affect the extraction yield and efficiency of colour pigments (Wang and Liu, 2009). Therefore, these factors have to be taken into consideration while extracting the pigment from raw material. The effect of these factors on isolation of colour pigments is discussed in this review article.

\section{Factors affecting isolation of colour pigments}

\section{Effect of moisture and particle size}

Moisture content inside the solid tissues can hinder the extraction of bio-pigments and 
other antioxidants. That is why it is considered an important factor for extraction of colour pigments. The plant material may contain some water $(<10 \%)$ as it does not affect extraction, therefore, complete dehydration is not recommended before extraction. A small quantity of water can be advantageous when a solvent with low polarity is used. On the other hand, excess water may reduce extraction effectiveness (Wrolstad et al., 2005). In addition to the moisture content of samples, particle size may influence the performance and efficiency of extraction procedure. The grinding of solid material can intensify the transfer of solvent through increasing the exchange interface between the solvent and the solid and also reducing the distance of penetration of the solvent in the solid. It is stated in several extraction studies that the raw materials are grounded before the extraction of biopigments. The smaller size of particles will increase contact area between the solid and solvent. Hence, it will increase the mass transfer of active component into the solvent. Particle size and shape of polymer sample were also noticed important by Grade et al., (1998). They observed efficient extraction of bio-active compounds from plant tissues when greater surface to volume ratio was used. Giao et al., (2003) found that a smaller particle size of approximately $0.2 \mathrm{~mm}$ led to a higher extraction of antioxidant compounds from plant tissues.

Most of the carotenoids are associated with the water insoluble fraction of the plant tissues and high moisture level renders its extraction quite problematic. Therefore, plant tissues must be preserved by drying before colour pigment extraction or processed as soon as it is produced (Kaur et al., 2008). Zhang et al., (2011) recommended freeze drying of tomato pomace followed by milling of dried solid tissues for efficient release of lycopene pigment. Carrot slices were tray dried and grounded in a laboratory grinder prior to extraction of $\beta$-carotene content by Kaur et al., (2013). Tupe et al., (2015) found maximum yield of lycopene when supercritical fluid extraction was performed with smaller particle size of tomato tissues. Sharmin et al., (2016) recommended 40 mesh particle size of solid mass to extract carotenoids from carrot.

\section{Effect of solid-solvent ratio}

In the extraction process of active molecules such as carotenoids from a solid material, diffusion takes place from solid to solvent or liquid. Extraction is a solid-solvent/liquid interaction in which one or more solid, crystal and liquid components (solute) are dissolved in a solvent to produce a solution or extract. A concentration gradient exists between solvent and solute due to which solute transfers from solid (concentrated) to liquid phase. Towards the end of the process, conditions tend to equilibrium and diffusion is almost terminated (Zhang et al., 2011). Extracted component yield will not continue to increase once saturation is reached. According to Hamdan et al., (2008), the solid-solvent ratio could significantly affect the equilibrium constant. A high solid-solvent ratio was observed to be favourable in isolation of antioxidants. A high solid-solvent ratio could give an increasing concentration gradient, resulting in an increase of diffusion rate that allows greater isolation of pigments by solvent. Overall, the main effect of the high solid-solvent ratio is to modify the solubility and equilibrium constant and thus increase the extraction yield of colour pigments (Cacace and Mazza, 2003). Although amount of bio-pigment compounds generally increase with increase of solidsolvent ratio but the increase in yield of that compound may not be directly proportional. Thus it is important to evaluate the influence of solid-solvent ratio during optimization of extraction of phyto-chemicals from different 
plant materials. Furthermore, use of high solid-solvent ratios would result in dilute solutions (Ho et al., 2008).

Rosenberg et al., (1983) studied the efficiency of different solvent to peel ratio and particle sizes. They revealed that most suitable solidsolvent ratio consisted of $1: 2(\mathrm{w} / \mathrm{v})$ for extraction of carotenoids from tomato. A solid-solvent ratio of 1:20 (w/v) for extraction of lycopene from tomato has been suggested by Fish et al., (2003) while 1:29 (w/v) solidsolvent ratio was optimized by Wang and Liu (2009) for the isolation of carotenoids from rape seed. Driouich et al., (2016) recommended 1:10 (w/v) solid-solvent ratio for the extraction of lycopene from tomato. During extraction of carotenoids from fresh carrot, Das and Bera (2013) optimized 1:40 (w/v) solid-solvent ratio for efficient release of pigment. Kumcuoglu et al., (2014) suggested 1:35 (w/v) solid- solvent ratio for ultrasonic extraction of lycopene from tomato waste while Sharmin et al., (2016) recommended use of 1:15 (w/v) solid-solvent ratio for extraction of carotenoids from carrot and tomato.

\section{Effect of temperature and time}

The extraction yield of antioxidant compounds from plant materials is influenced mainly by the conditions under which the process of liquid-solid extraction is carried out to separate a soluble fraction from a permeable solid (Singh et al., 2002). The heat, below the degradation temperature, facilitates the extraction of solute by permeabilization of cell walls, increasing the solubility of solutes as well as diffusion coefficients and decreasing the viscosity of the solvent extraction upto a particular extraction duration.

Hart and Scott (1995) revealed an increase in the concentration of carotenoid in heated vegetables which could be due to changes in the cell structure and thereby enhancing the availability of carotenoids. Similarly, Santamaria et al., (2000) have observed significant effect of temperature on extraction of colour pigment. Nguyen and Schwartz (1998) noticed that heat treatment changes the physical structure of the tomato tissue and the bioavailability of carotenoids. Different heating intensities and solvents were used by Calvo et al., (2007) to study the influence on carotenoids isomerization and degradation during extraction. They extracted lycopene, $\beta$ carotene, phytoene and phytofluene from tomato peel powder and reported that carotenoid concentration increased with increasing the temperature upto $50{ }^{\circ} \mathrm{C}$, however, using ethanol at $60{ }^{\circ} \mathrm{C}$ resulted in lower yield of lycopene. Fikselova et al., (2008) also found that applied temperature of approximately $40-60{ }^{\circ} \mathrm{C}$ and extraction time of 2-4 $\mathrm{h}$ positively influences the extraction yield of carotenoids from carrot with 2propanol extraction.

Wijngaard et al., (2012) suggested the temperature below $55-59{ }^{0} \mathrm{C}$ to be favourable for carotene extraction from natural sources. Das and Bera (2013) while applying varied temperature $\left(30\right.$ to $\left.50{ }^{0} \mathrm{C}\right)$ during solvent extraction of pigment from carrot mass noticed an increase in $\beta$-carotene extraction when temperature was raised up to $40{ }^{\circ} \mathrm{C}$ with $4 \mathrm{~h}$ extraction time. However, Kumcuoglu et al., (2014) recommended $60{ }^{\circ} \mathrm{C}$ temperature for $30 \mathrm{~min}$ during ultrasonic extraction of lycopene from tomato waste. Sharmin et al., (2016) studied the effect of thermal treatments on extraction of $\beta$-carotene from fresh carrot samples. With the solvent extraction at $40{ }^{\circ} \mathrm{C}$, the yield of carotenes $(2.45 \mathrm{mg} / 100 \mathrm{~g})$ was recorded higher as compared to that at $20{ }^{\circ} \mathrm{C}(1.58 \mathrm{mg} / 100 \mathrm{~g})$ while the highest extraction yield (4.28 $\mathrm{mg} / 100 \mathrm{~g}$ ) was found at $60{ }^{\circ} \mathrm{C}$. Extraction period of $2 \mathrm{~h}$ gave maximum recovery of 
carotenoids. After this time, the yield of $\beta$ carotene was found to decrease.

\section{Effect of enzymes}

In general, a complex plant cell wall is made up of cellulose, pectin, hemicellulose and protein. An enzymatic activity such as cellulase, hemicellulase, pectinase and even protease can disrupt the cell wall (Rosenthal et al., 1996) causing cell components to be released. The duration of a treatment depends on the activity of the enzymes, temperature, $\mathrm{pH}$, structure of plant cell and the final desired viscosity. Enzyme-assisted extraction methods have shown to achieve high extraction yields for compounds including polysaccharides, oils, bio-pigments and flavours (Yang et al., 2010). Dominguez et al., (1993) while compiling the studies using enzyme to enhance oil extraction from fruits and oil seeds reported that for each fruit or seed, there are many choices of enzymes and enzyme mixtures.

Delgado-Vargas and Paredes-Lopez (1997) used ECONASE-CEP to enhance carotenoid extraction in marigold flowers. This commercial product constituted an enzymatic mixture of cellulase, hemicellulase, pectinase and was applied on fresh marigold before extraction of carotenoids. The effect of different parameters on enzyme-assisted extraction of lycopene from tomato processing waste has been studied by Ranveer et al., (2013). They concluded that enzymatic treatment of 1.5 per cent cellulase and 2 per cent pectinase prior to extraction of lycopene from tomato peel significantly increased yield. Sowbhagya et al., (2013) extracted pigment from marigold flower. They reported that 0.2 per cent aqueous solution of viscozyme i.e. an enzymatic mixture of cellulase, hemicellulase, protease, arabinase and xylanase increased the diffusion coefficient from $1.56 \times 10^{-9} \mathrm{~m}^{2} / \mathrm{s}$ to $4.02 \times 10^{-}$
${ }^{9} \mathrm{~m}^{2} / \mathrm{s}$ and mass transfer coefficient from 0.14 $\mathrm{h}^{-1}$ to $0.36 \mathrm{~h}^{-1}$. At the same time, resin and pigment yield were also found to increase along with more retention of colour.

Lenucci et al., (2015) evaluated the effect of enzymes on the extraction yield of lycopene from freeze dried matrices prepared from tomato purée. They found that the combined use of food grade commercial plant cell wall glycosidases (celluclast/novozyme plus viscozyme at concentration of $0.25 \%$ by volume) allowed to increase lycopene and lipid concentration in the matrix and rose substrate load onto the extraction vessel (46 $\%)$ as compared to the control. They further revealed that the total amount of extracted lycopene was approximately three times higher in enzymatically treated tomato matrix than control.

In conclusion, fruits and vegetables are abundant source of carotenoids. Carotenoids have attracted a great attention due to their functional and health benefiting properties. Such an interest in carotenoids is due to the favourable properties of these pigments such as natural origin, nutritional value and high versatility. Carotenoids have been extracted from different fruits and vegetables by many researchers in last few years. It has been found in previous studies that optimization of various factors such as moisture, particle size, solid-solvent, temperature, time and enzymes affect the extraction efficiency positively during isolation of bio-pigments.

\section{References}

Bachalla, N. (2016). Identification of synthetic food colors adulteration by paper chromatography and spectrophotometric methods. International Archives of Integrated Medicine, 3: 182-191.

Cacace, J.E. and Mazza, G. (2003). Mass 
transfer process during extraction of phenolic compounds from milled berries Journal of Food Engineering, 59: 379-389.

Calvo, M.D., Dado and Santa-Maria, G. (2007). Influence of extraction with ethanol or ethyl acetate on the yield of lycopene, carotene, phytoene and phytofluene from tomato peel powder. European Food Research and Technology, 224: 567-571.

Clydesdale, F.M. (1993). Color as a factor in food choice. Critical Reviews in Food Science and Nutrition, 331: 83-101.

Das, S. and Bera, D. (2013). Mathematical model study on solvent extraction of carotene from carrot. International Journal of Research in Engineering and Technology, 2: 343-349.

Delgado-Vargas, F. and Paredes-Lopez, O. (1997). Effects of enzymatic treatments on carotenoid extraction from marigold flowers (Tagetes erecta). Food Chemistry, 58: 255-258.

Delgado-Vargas, F. and Paredes-Lopez, O. (1997). Effects of enzymatic treatments on carotenoid extraction from marigold flowers (Tagetes erecta). Food Chemistry, 58: 255-258.

Devraj, S., Li, D. and Jialal, I. (1996). The effects of alpha tocopherol supplementation on monocyte cell function: Decreased lipid oxidation, interleukin $1 \mathrm{~b}$ secretion and monocyte adhesion to endothelium. Journal of Clinical Investigation, 98:756-763.

Dominguez, H., Nunez, M.J. and Lema, J.M. (1993). Enzymatic pretreatment to enhance oil extraction from fruits and oilseeds: a review. Food Chemistry, 49: 271-286.

Downham, A. and Collins, P. (2000). Colouring our foods in the last and next millennium. International Journal of Food Science and Technology, 35: 5-22.
Driouich, R., Bousselmi, O. and Cherif, A. (2016). Valorization of tomato processing waste for lycopene extraction. Mediterranean Journal of Chemistry, 6: 686-691.

Dweck, A.C. (2009). Comprehensive focus on natural dyes. Colour Cosmetics, 5769.

Fikselova, M., Silhar, S., Marecek, J. and Francakova, H. (2008). Extraction of carrot (Daucus carota L.) carotenes under different conditions. Czech Journal of Food Sciences, 26: 268274.

Fish, W.W., Perkins-Veazie, P. and Collins, J.K. (2003). A quantitative assay for lycopene that utilizes reduced volumes of organic solvents. Journal of Food Composition and Analysis, 3: 309317.

Frick, D. and Meggos, H. (1988). FD \& C colors. Food Technology, 7: 49-56.

Garewal, H.S., Ampel, N.M., Watson, R.R., Prabhala, R.H. and Dols, C.L. (1992). A preliminary trial of b-carotene in subjects infected with Human Immunodeficiency Virus. Journal of Nutrition, 122: 728-731.

Giao, M.S., Fonseca, S.C., Pintado, M.E. and Malcata, F.X. (2003). Effect of particle size upon the extent of extraction of antioxidant power from the plants Agrimonia eupatoria, Salvia sp. and Satureja Montana. Food Chemistry, 117:412-416.

Giusti, M.M. (1996). Radish anthocyanin extract as a natural red colorant for maraschino cherries. Journal of Food Science, 61: 688-694.

Grade, J.A., Catala, R. and Gavara, R. (1998). Analysis of antioxidants extracted from polypropylene by supercritical fluid extraction. Food Additives and Contaminants, 15: 701-708.

Hamdan, S., Daood, H., Toth-Markus, M. and Illés, V. (2008). Extraction of 
cardamom oil by supercritical carbon dioxide and sub-critical propane. Journal of Supercritical Fluids, 44: 25 30.

Hart, D.J. and Scott, K.J. (1995). Development and evaluation of an HPLC method for the analysis of carotenoids in foods and the measurement of the carotenoid content of vegetables and fruits commonly consumed in the UK. Food Chemistry, 54: 101-111.

Ho, C.H.L., Cacace, J.E. and Mazza, G. (2008). Mass transfer during pressurized low polarity water extraction of lignans from flaxseed meal. Journal of Food Engineering, 89: 64-71.

Ilker, R. (1987). In-vitro pigment production: an alternative to color synthesis. Food Technology, 41: 70-72.

Kaur, D., Wani, A.A., Oberoi, D.P.S. and Sogi, D.S. (2008). Effect of extraction conditions on lycopene extractions from tomato processing waste skin using response surface methodology. Food Chemistry, 108: 711-718.

Kaur, K., Shivhare, U.S., Basu, S. and Raghavan, G.S.V. (2013). Kinetics of Extraction of $\beta$-carotene from tray dried carrots by using supercritical fluid extraction technique. Food and Nutrition Sciences, 3: 591-595.

Kumcuoglu, S., Yilmaz, T. and Tavman, S. (2014). Ultrasound assisted extraction of lycopene from tomato processing wastes. Journal of Food Science and Technology, 51: 4102-4107.

Lawrence, G., Salles, C., Septier, C., Busch, J. and Thomas-Danguin, T. (2009). Odour-taste interactions: A way to enhance saltiness in low-salt content solutions. Food Quality and Preference, 20: 241-248.

Lenucci, M.S., Caroli, M.D., Marrese, P.P., Iurlaro, A., Rescio, L., Böhm, V.,
Dalessandro, G. and Piro, G. (2015). Enzyme-aided extraction of lycopene from high pigment tomato cultivars by supercritical carbon dioxide. Food Chemistry, 170: 193-202.

Nguyen, M.L. and Schwartz, S.J. (1998). Lycopene stability during food processing. Processing Society Experimental Biology and Medicinal, 218: 101-105.

Palozza, P. and Krinsky, N.I. (1992). Antioxidant effects of carotenoids in vivo and in vitro: An overview. Methods in Enzymology, 213: 403420.

Ranveer, R.C., Patil, S.N. and Sahoo, A.K. (2013). Effect of different parameters on enzyme-assisted extraction of lycopene from tomato processing waste. Food and bioproducts processing, 91: 370-375.

Rao, A.V., and Rao, L.G. (2007). Carotenoids and human health. Pharmacological research, 55: 207-216.

Rock, C.L. (1997). Carotenoids: Biology and treatment. Pharmacology and Therapeutics, 75: 185-197.

Rosenberg, M., Mannheim, C.H. and Kopleman, I.J. (1983). Carotenoids based food colourants extracted from orange peel by d-limolene extraction process and use. LebensmittleWissenchaft -und- Technologies, 16: 270-275.

Rosenthal, A., Pyle, D.L. and Niranjan, K. (1996). Aqueous and enzymatic processes for edible oil extraction. Enzyme and Microbial Technology, 19: 402-420.

Santamaria, R.I., Durante, M.D.R., Barzana, E., Fernado, D., Gama, F.M., Mota, M. and Manguria, A.L. (2000). Selective enzyme mediated extraction of capsaicinoids and carotenoids from chilliguajillopuya (Capsicum annum L.) using ethanol as solvent. Journal of 
Agriculture and Food Chemistry, 48: 3063-3067.

Sharmin, T., Ahmed, N., Hossain, A., Hosain, M.M., Mondal, S.C., Haque, M.R., Almas, M. and Siddik, A.B. (2016). Extraction of bioactive compound from some fruits and vegetables (pomegranate peel, carrot and tomato). American Journal of Food and Nutrition, 4: 8-19.

Singh, R.P., Chidambara-Murthy, K.N. and Jayaprakasha, G.K. (2002). Studies on the antioxidant activity of pomegranate (Punica granatum) peel and seed extract using in vitro models. Journal of Agricultural and Food Chemistry, 50: 81-86.

Sowbhagya, H.B., Sushma, S.B., Rastogi, N.K. and Naidu, M.M. (2013). Effect of pretreatments on extraction of pigment from marigold flower. Journal of Food Science and Technology, 50: 122-128.

Tupe, R.B., Patil, S.M. and Sakhal, B.K. (2015). Extraction of lycopene by supercritical fluid extraction. International Journal of Science, Spirituality, Business and Technology, 3: 43-48.

Wang, L. and Liu, Y. (2009). Optimization of solvent extraction conditions for total carotenoids in rapeseed using response surface methodology. Natural Science, 1: 23-29.
West, K.P., Howard, G.R. and Sommer, A (1989). Vitamin A and infection: public health implications. Annual Reviews of Nutrition, 9: 63-86.

Wijngaard, H., Hossain, M.B., Rai, D.K. and Brunton, N. (2012). Techniques to extract bioactive compounds from food by products of plant origin. Food Research International, 46: 505-513

Wrolstad, R.E., Acree, T.E., Decker, E.A., Penner, M.H., Reid, D.S., Schwartz, S.J., Shoemaker, C.F., Smith, D, and Sporns, P. (2005). Carotenoids, in handbook of food analytical chemistry pigments, colorants, flavors, components texture and bioactive food. John Wiley and Sons, Inc: New Jersey.

Yang, Y.C., Li, J., Zu, Y.G., Fu, Y.J., Luo, M., Wu, N. and Liu, X.L. (2010). Optimisation of microwave-assisted enzymatic extraction of corilagin and geraniin from Geranium sibiricum Linne and evaluation of antioxidant activity. Food Chemistry, 122: 373380.

Zhang, K., Jiang, H. and Ren, Y. (2011). The effect of technical parameters on lycopene extraction in supercritical fluid extraction from freeze-dried tomato pomace (peels and seeds). Advanced Materials Research, 236: 2869-2871.

\section{How to cite this article:}

Anshu Sharma, Anju Kumari Dhiman, Sachin Mittal, Surekha Attri and Neeru Dubey. 2019. Carotenoid Pigment: Significance as a Natural Food Colourant and Factors Affecting its Isolation. Int.J.Curr.Microbiol.App.Sci. 8(02): 44-51. doi: https://doi.org/10.20546/ijcmas.2019.802.008 